\title{
Traduzindo Fleck: entrevista com Georg Otte e Mariana Camilo de Oliveira
}

\author{
Translating Fleck: an interview with Georg Otte \\ and Mariana Camilo de Oliveira
}

\author{
Entrevista com \\ Georg Otte \\ Professor da Faculdade de Letras/ \\ Universidade Federal de Minas \\ Gerais (UFMG). \\ georg.otte@uol.com.br

\section{Mariana Camilo de Oliveira} \\ Mestre em Estudos Literários/UFMG \\ marianacamilo@yahoo.com.br \\ Av. Antônio Carlos, 6627/s.4029 \\ 31270-901 - Belo Horizonte - MG \\ - Brasil \\ Concedida a

\section{Miriam Junghans} \\ Doutoranda do Programa de \\ Pós-graduação em História das \\ Ciências e da Saúde (PPGHCS)/ \\ Casa de Oswaldo Cruz/Fiocruz. \\ Av. Brasil, 4036/4ªndar \\ 21040-361 - Rio de Janeiro - RJ - \\ Brasil \\ miriamjung@gmail.com
}

JUNGHANS, Miriam. Traduzindo Fleck: entrevista com Georg Otte e Mariana Camilo de Oliveira. História, Ciências, Saúde - Manguinhos, Rio de Janeiro, v.18, n.4, out.-dez. 2011, p.1151-1158.

\section{Resumo}

Pesquisas recentes da história das ciências e da sociologia do conhecimento, que entendem a ciência como conhecimento em circulação, apontam a importância do estudo das traduções de obras científicas, que envolvem tanto as circunstâncias sociais de produção quanto as de recepção dessas obras. O depoimento que apresentamos é dos autores da tradução feita diretamente do alemão para o português de Gênese e desenvolvimento de um fato científico, de Ludwik Fleck, citada por Thomas Kuhn no prefácio de A estrutura das revoluções científicas. Com ele, pretende-se oferecer subsídios para a compreensão da importância de Fleck nos estudos sobre a circulação do conhecimento científico desenvolvidos no Brasil.

Palavras-chave: história das ciências; sociologia do conhecimento; tradução; Ludwik Fleck (1896-1961); Brasil.

\section{Abstract}

Recent research in the history of science and the sociology of knowledge, where science is understood as knowledge in circulation, has called attention to the importance of studying the translation of scientific works, which involves not only the social circumstances of their production but also how these works are received. The testimony presented here was given by the translators of the Portuguese version of Ludwik Fleck's Entstehung und Entwicklung einer wissenschaftlichen Tatsache (Genesis and development of a scientific fact), a work that probably influenced Thomas Kuhn's now classic The structure of scientific revolutions. Our goal is to offer resources for understanding Fleck's importance in Brazilian studies on the circulation of scientific knowledge.

Keywords: history of science; sociology of knowledge; translation; Ludwik Fleck (1896-1961); Brazil. 
A produção historiográfica tem reconhecido, desde a década de 1980, a importância do estudo das traduções de textos literários ou religiosos, que envolvem tanto as circunstâncias sociais de produção quanto as de recepção dessas obras. A história social das ciências, no entanto, apenas nos últimos anos passou a examinar a tradução de textos científicos, entendendo a ciência como "uma forma de comunicação" e como "conhecimento em circulação" (Secord, 2004, p.665). A tradução de um texto equivaleria a um processo de relocação cultural, pois cria uma obra com características diferentes do original através de notas, seleções e adições, novos títulos e estruturas textuais (Bertomeu-Sánchez et al., 2006, p.663). Como podemos ler na Carta do Editor desta edição de História, Ciências, Saúde - Manguinhos, a adaptação de um texto (ou de uma obra científica) para uma língua estrangeira deve levar em consideração não apenas as características da língua de partida e da língua de chegada, mas também a trama mais ampla e complexa das culturas científicas que estão sendo colocadas em contato por meio da tradução.

O depoimento apresentado pretende oferecer subsídios para a compreensão da importância da tradução da obra de Ludwik Fleck (1896-1961), Gênese e desenvolvimento de um fato científico (Fleck, 2010), nos estudos desenvolvidos no Brasil sobre a circulação do conhecimento científico.

Em 1935, Ludwik Fleck, médico e microbiologista polonês de origem judaica, publicou, em alemão, um livro que viria a ter uma rica e conturbada história de recepção. O fato de ser judeu e ter publicado o livro em alemão pode ter contribuído para o ostracismo no qual caiu a obra logo após ser publicada.

O idioma alemão foi, da segunda metade do século XIX em diante, a língua franca das ciências, circulando além do âmbito dos países de língua germânica propriamente dito. Lewis Pyenson (1985) examina algumas razões disso. Como a unificação da Alemanha ocorreu tardiamente, em 1871, a grande força da ciência alemã estava nas publicações, principalmente nos periódicos, que tiveram um papel fundamental no contexto científico alemão, na virada do século XIX para o XX. Na ausência de um Estado centralizado, existiam poucas maneiras de um pesquisador em Berlim saber o que um colega de Munique estava fazendo e os periódicos científicos eram essenciais para a circulação dessas informações. Todas as universidades - e praticamente cada departamento delas - publicavam seus periódicos. A unificação do Estado alemão, até então uma colcha de retalhos de variadas unidades político-administrativas, mas que partilhavam do mesmo substrato cultural, ocorreu de forma diferente de outros países europeus. No caso francês, por exemplo, com as informações científicas relativamente centralizadas em Paris, era possível aos cientistas recorrer a organismos estatais, instituições centrais, para obter informações sobre o estado da arte de alguma área. Na Alemanha era necessário recorrer às publicações. Isso se estendeu até o Tratado de Versalhes, em 1919, quando a utilização do alemão como língua científica nos congressos científicos e em publicações científicas sofreu forte oposição (cf. SchroederGudehus, 1978), o que teve grande impacto na produção da ciência europeia, que levou algum tempo para se reorganizar, formar suas redes e adquirir uma força equivalente à que a Alemanha tinha anteriormente. Assim o alemão era a língua franca da ciência nas primeiras décadas do século XIX e continuou a ser por um bom tempo depois de 1919. 
Ludwik Fleck publicou Gênese e desenvolvimento... em 1935, em uma época pouco auspiciosa para as publicações científicas em idioma alemão: depois do Tratado de Versalhes, durante a ascensão do regime nazista na Alemanha, e antes da Segunda Guerra Mundial, que iria redefinir o panorama das ciências mundiais com o fortalecimento do idioma inglês como língua franca da produção científica. Além disso, Fleck posicionou-se contra o pensamento então dominante do Círculo de Viena. Ele ressaltava - em desacordo com a orientação intelectual do grupo vienense - a importância dos aspectos históricos e sociais na produção do conhecimento científico (Condé, 2010, p.VIII).

Citada por Thomas Kuhn em 2006 (p.11), no prefácio do seu livro hoje clássico $A$ estrutura das revoluções científicas, a obra de Fleck vem recebendo traduções para diversos idiomas. A importância dos prefaciadores dessas traduções, autores de grande trânsito na história social das ciências, nos dá a dimensão da importância atribuída ao livro: o próprio Thomas Kuhn fez o prefácio da edição em inglês de 1979, Paulo Rossi o da edição italiana, de 1983, e Ilana Löwy o prefácio da edição francesa, de 2006, cujo posfácio foi escrito por Bruno Latour. Na tradução brasileira, publicada em 2010, o prefácio é o da edição alemã de 1980, de Lothar Schäfer e Thomas Schnelle, publicado também na edição em espanhol de 1986 (Condé, p.XV, nota 4).

A entrevista que apresentamos, concedida na Faculdade de Letras da Universidade Federal de Minas Gerais (UFMG), em Belo Horizonte, em 1ํ de dezembro de 2010, é dos autores da tradução feita diretamente do alemão para o português de Gênese e desenvolvimento de um fato científico (2010), Georg Otte e Mariana Camilo de Oliveira.

\section{Miriam Junghans Doutoranda do PPGHCS/COC/Fiocruz.}

Gostaria que falassem da formação de vocês e de como chegaram a fazer a tradução de Gênese e desenvolvimento de um fato científico, de Ludwik Fleck.

Georg - Fiz mestrado na Alemanha, em letras germânicas e românicas, e o doutorado em literatura comparada pela UFMG. Sou professor da Faculdade de Letras da UFMG na graduação de língua e literatura alemãs desde 1986. Meus trabalhos de tradução são esporádicos; fiz, por exemplo, a tradução da obra de Hans Ulrich Gumbrecht As funções da retórica parlamentar na Revolução Francesa, de 2003.

O Rodrigo Ribeiro, editor da Fabrefactum, me pediu para indicar alguém para fazer a tradução do livro de Ludwik Fleck. Achei interessante, pois sempre tive um pé na filosofia e na teoria do conhecimento. Tenho grande interesse por Walter Benjamin, outro judeu contemporâneo de Fleck, e vi algumas afinidades, tanto que preparei um projeto de pósdoutorado que relaciona os dois, abordando a questão da continuidade e descontinuidade. ${ }^{1}$

\footnotetext{
${ }^{1}$ Georg Otte é atualmente pesquisador visitante da Centro de Pesquisas Literárias e Culturais (ZfL), em Berlim, com projeto em andamento. Nesse centro são desenvolvidas pesquisas que relacionam as áreas das ciências humanas e culturais como, por exemplo, estudos sobre Übertragungswissen ('saber de transferência'), ou seja, a questão de transferência de saberes entre ciências humanas, naturais e exatas.
} 
Apesar de serem temas filosóficos de áreas distintas - a produção de Benjamin está mais relacionada a questões estéticas, e a de Fleck, à teoria do conhecimento - são próximas e há paralelos que a meu ver permitem uma comparação. Resolvi então fazer eu mesmo a tradução, apesar de saber que é um trabalho ingrato, que exige muito tempo de pesquisa. Convidei a Mariana, que havia sido minha orientanda de mestrado, para colaborar. Era uma boa complementação, eu como falante nativo do alemão e ela do português. Como o texto do Fleck é muito denso e complexo, fizemos várias experiências para ver como o trabalho seria mais produtivo e acabamos chegando ao seguinte método: fiz a primeira tradução e ela fez a revisão da tradução, o que por vezes é mais trabalhoso do que fazer a tradução propriamente dita.

Mariana - O Fleck é um teórico que sempre pensa o coletivo, acho que ele aprovaria nosso método de tradução...

Minha primeira formação foi em psicologia, na UFMG. Desde então eu tinha interesse por autores germanófonos, estudava alemão e decidi investir no estudo de germanística. Fiz minha pesquisa de mestrado em teoria da literatura, na Faculdade de Letras da UFMG, estudando um autor que, como Ludwik Fleck, também era judeu, mas de língua alemã, Paul Celan. Ele também foi um sobrevivente dos campos de concentração e era de uma região próxima àquela em que viveu Fleck, que pertenceu igualmente ao Império AustroHúngaro, como a Ucrânia, a Romênia etc. Esses autores transitavam entre esses mundos linguísticos. Talvez tivessem com o alemão um contato mais acadêmico ou literário, mas eventualmente sabiam hebraico, ídiche, ucraniano, russo.

Georg - O Fleck é de Lwów, e Paul Celan de Czernowitz, ambas na região da Galícia polonesa. Trata-se, portanto, do mesmo âmbito cultural. São cidades que chamaríamos hoje multiculturais: tinham uma alta porcentagem de população judaica e, como ocorria em geral no Império Austro-Húngaro, falavam-se normalmente três línguas, o alemão, o polonês e outras línguas como o romeno; era uma grande mistura étnica e cultural.

\section{E como foi o processo de tradução?}

Georg - O texto de Gênese e desenvolvimento varia bastante. Certos trechos são mais genéricos, mais fáceis de traduzir. Em determinado momento Fleck conta casos, encontros entre cientistas, interessantes porque são o lado humano da pesquisa, formam o coletivo de pensamento, o Denkkollektiv. Outros trechos apresentaram uma dificuldade maior, como por exemplo quando fala sobre reações químicas. É uma linguagem técnica, exige muita pesquisa de sentido e de vocabulário. Acho que a compreensão plena de determinados trechos do livro, como é o caso da questão científica central, a reação de Wassermann, pressupõe um conhecimento científico do qual não dispomos. Mas é possível fazer uma tradução sintaticamente correta sem saber exatamente o que está acontecendo ali. A velocidade da tradução variou muito devido a essas diferenças do texto. Além disso a versão alemã que usamos para nossa tradução é um fac-símile da primeira edição, suíça, de 1935, e precisaria passar por uma revisão. Talvez essa forma de publicação tenha sido uma decisão editorial, procurando manter a fidelidade à edição suíça. Mas esse fator dificultou a tradução.

Mariana - Os prefaciadores alemães mencionam a diferença do texto de Fleck em relação a monografias de epistemólogos e filósofos da ciência contemporâneos; a sistematização 
diferente que ele adota. Uma particularidade, que é um desafio para o tradutor, é o fato de ele nunca ter abandonado o trabalho laboratorial. Entre suas publi-cações, além desse livro apenas sete textos são dedicadas à sociologia do conhecimento. Costumava publicar mais na área da microbiologia, de onde vem essa carga de vocabulário técnico que tivemos que pesquisar - além de termos que aprender a transitar no estilo de pensamento no qual ele transita. Outra dificuldade foram os documentos em latim que ele utiliza em sua argumentação, que muitas vezes não têm tradução para o alemão moderno.

$\mathrm{Na}$ tradução espanhola eles mantiveram os textos em latim, o que em termos de tradução é mais simples, por tratar-se apenas de transcrição. Embora isso tenha aumentado a carga e a dificuldade do trabalho de vocês, penso que valorizou a tradução brasileira.

Mariana - Sim, contamos com o auxílio de um colega latinista, Antônio Martinez de Rezende.

Mauro Condé, na introdução, diz que é perceptivel que, embora o alemão não fosse a língua-mãe do Fleck, ele provinha de um substrato cultural muito diversificado no qual o alemão era, por excelência, a língua franca da ciência. É possível perceber que ele escrevia em uma língua que não era a dele?

Mariana - Acho que a questão não é avaliar o domínio dele do alemão. Certamente tinha um domínio muito grande, sobretudo da linguagem técnica e teórica do alemão. Mas acho que tem consequências o fato de ele ter outra língua. Isso deixa traços na maneira de escrever e de pensar.

Georg - Em relação à língua alemã, devemos recordar que havia um grande centro intelectual, pelo menos para o Império Austro-Húngaro, que era Viena. O que Fleck escreveu polemizava justamente com a produção intelectual do chamado Círculo de Viena. Certamente foi corajoso da parte dele ter-se oposto ao Círculo, que tinha um peso muito grande não só no Império mas também na Alemanha e na comunidade científica como um todo. O pesquisador suíço Johannes Fehr (diretor do Ludwik Fleck Zentrum, de Zurique) $)^{2}$, que foi convidado para o colóquio no qual ocorreu o lançamento do livro, mencionou que Fleck sofreu discriminação por ser judeu; depois do fim do Império AustroHúngaro, em 1918, os poloneses não permitiram a continuidade da sua carreira acadêmica.

Vocês já citaram as dificuldades que encontraram com a linguagem da microbiologia. Além daquelas relativas à linguagem técnica, alguma outra chamou particularmente a atenção de vocês?

Mariana - Um grande desafio foram os termos que Fleck introduziu, os neologismos. Alguns geraram muita discussão entre nós, a exemplo dos que são constituídos com o morfema Denk, como em Denkstil (estilo de pensamento), Denkkollektiv (coletivo de pensamento), Denkverkehr (trocas intelectuais) e outros. E ele combina esses com outros termos; o tradutor tem de estar sempre atento a essas repetições no texto, para manter a regularidade de sua tradução. Esses termos, traduzidos de uma certa maneira, são parte

\footnotetext{
${ }^{2}$ Disponível em http://www.ludwikfleck.ethz.ch.
} 
importante do que permanece de uma tradução. São eles que depois vão se incorporar ao vocabulário dos coletivos de pensamento. É um desafio. É preciso perceber também em que momentos eles devem ser modificados para se ajustar ao texto, pois, se mantidos como se apresentam no alemão, talvez tornem incompreensível o texto em português. Fleck cria uma trama bastante complicada de conceitos, é necessário um certo jogo de cintura, por parte do tradutor, ao lidar com o jargão técnico e neologismos por ele utilizados.

Georg - Esses exemplos, como Denkkollektiv, encontraram certa resistência por parte dos editores, que se opunham a aceitar a expressão coletivo de pensamento. É um neologismo em alemão e admito que em português não soa bem. Pensamento coletivo soa muito melhor do que coletivo de pensamento.

Mariana - No idioma alemão, quando temos um termo composto, seu núcleo geralmente tem que estar no final da palavra, e todos os outros termos funcionam como determinantes dele. Então, por mais estranho que soe 'coletivo de pensamento', já que 'pensamento coletivo' talvez seja mais usual, é uma tomada de posição da tradução, é necessário defendê-la. É preciso demarcar a diferença, pois é uma expressão específica da sociologia do conhecimento.

Para ficarmos nesse 'campo semântico', há outro caso que gostaria que comentassem. Vocês traduziram Lehre como doutrina, como se pode ver no subtítulo, "introdução à doutrina do estilo de pensamento". Em outros momentos Lehre foi traduzido como teoria. Vocês discutiram essa diferença entre doutrina e teoria?

Mariana - Essa foi uma das discussões de regularidades. Em alguns momentos ele usava Theorie, em outros, Lehre. Então criamos uma convenção; toda vez que Fleck empregou Lehre traduzimos por doutrina e quando empregou Theorie, teoria.

Georg - É certo que, em português, doutrina soa como dogma, doutrinação. Acho que Lehre não tem esse peso, não tem a mesma conotação. Lehre é ensinamento, literalmente.

Na introdução de Lothar Schäfer e Thomas Schnelle (Fleck, 2010, p.25), pode-se ler: "assim a introdução numa determinada área de trabalho possui antes o caráter de uma doutrinação do que de um incentivo ao pensamento crítico científico". Isso justifica, de certa forma, o uso da palavra doutrina.

Georg - Esse é um assunto muito importante para Fleck. Ele fala disso em outros pontos do livro, por exemplo quando se refere aos manuais. Diz que a introdução a determinado coletivo de pensamento tem um aspecto paternalista, é uma imposição de determinada maneira de pensar, de ver as coisas. Como uma doutrinação. Antes de poder pensar por conta própria é necessário passar por esses rituais que, segundo ele, são quase rituais religiosos.

Outro termo que deve ter sido um desafio para vocês é Lustseuche, que foi traduzido como epidemia venérea. O termo Lust tem uma ampla gama de significados em alemão, como prazer, gozo, desejo, vontade, que se acopla a Seuche, epidemia, doença contagiosa, e acaba dando um grande peso moral à palavra.

Georg - Foi um termo que deu bastante trabalho para traduzir. Acho muito interessante a questão da sífilis, dos mitos que a envolvem, como mostrou Fleck. É claro que a sífilis é um exemplo extremo, no qual se misturam questões morais e científicas. 
Em espanhol, a tradução optou pelo uso de 'mal', o que deixa o termo mais próximo da ideia de doença do que propriamente de epidemia.

Mariana - O mal pode ser associado a veneno, sangue contaminado, no caso da sífilis.

Vocês leram as outras traduções de Fleck? Como se prepararam para fazer tradução de Gênese e desenvolvimento de um fato científico?

Georg - De início pensamos em ler outras traduções de Fleck, o que talvez facilitasse nosso trabalho, mas depois mudamos de ideia e decidimos não ler nenhuma. Existe um léxico Fleck (Flecksikon) na internet, ligado ao centro de estudos de Zurique. ${ }^{3}$ Mas procuramos manter certa distância das soluções apresentadas em outros idiomas.

Mariana - Nas pesquisas que fizemos era possível perceber as tensões nas traduções do vocabulário fleckiano para outros idiomas.

No Programa de Pós-graduação em História das Ciências e da Saúde da Casa de Oswaldo Cruz, da Fiocruz, lemos Fleck sistematicamente. Mas certamente essa não é uma regra geral. Como vocês veem isso?

Georg - Embora eu não seja da área da teoria do conhecimento, conversei com colegas de outras universidades e percebi que ainda é uma obra cujo conhecimento está limitado aos especialistas. Essa tradução tem esse mérito, de colocá-lo em circulação no Brasil.

Mariana - Acho que é tudo muito novo, muito recente. Fleck era, até pouco tempo atrás, apenas uma nota de rodapé ou era lido em outros idiomas.

Georg - O posfácio da edição francesa é de Bruno Latour, que defendeu a importância de Fleck afirmando que não ele deveria ser considerado simplesmente um precursor de Thomas Kuhn, mas sim um autor com importância própria. Talvez seja uma questão de marketing científico, de despertar o interesse pela obra.

O que significou, para vocês, essa tradução, o contato com as ideias de Fleck?

Georg - Para mim o mais importante foi ela ter me levado a pensar sobre alguns aspectos da Kulturwissenschaft, dos estudos culturais; que ainda não costumam incorporar a ciência, os estudos biológicos. Na questão da sífilis, por exemplo, a abordagem científica sempre estará muito carregada de fatores culturais. A ideia do sangue corrompido é um fator cultural predeterminado por conceitos religiosos, estéticos. Fleck mostra que se gastava muito mais dinheiro com o combate à sífilis do que com a tuberculose, que fazia muito mais vítimas. Isso mostra que havia fatores em jogo que não eram propriamente científicos - se é que é possível pensar a produção científica sem levar em consideração fatores culturais.

Mariana - Acho que o tradutor não tem como colocar luvas cirúrgicas e não se deixar contaminar pelo texto que está sendo trabalhado, ainda mais em uma obra dessa natureza. Em determinado momento discutimos em que medida Fleck se incluiria ou não em sua própria teoria. Acho que, de certo modo, ele não se exclui do que observa, e também estava dentro de um coletivo de pensamento. Não está alheio às condições sociológicas desse

\footnotetext{
${ }^{3}$ Disponível em http://www.ludwik-fleck-kreis.org/uploadfiles/documents/1909_015340_Flecksikon.pdf
} 
fazer científico. Achei suas propostas bastante radicais, e é notável o fato de o texto dele ter sobrevivido apesar de tantas circunstâncias adversas. Enquanto alguns cientistas questionavam o Círculo de Viena, os positivistas, os puristas lógicos, do ponto de vista do dinamismo da ciência, ele questionou a própria noção do que é um fato, do que é um fato científico. Fleck nos faz perceber que 'fato' é um feito; nossa língua diz isso, mas perdemos essa percepção. Um fato é uma construção.

Georg - Podemos compreender a importância de Fleck para a sociologia do conhecimento aplicando suas próprias ideias, ou seja, reconhecendo a coragem que teve de questionar certas correntes de pensamento que eram hegemônicas na sua época, principalmente o Círculo de Viena, o neopositivismo, Carnap etc. E fez isso sem ser um especialista em teoria do conhecimento, pois era um cientista. Além disso, o próprio título do livro é uma provocação, "a gênese de um fato". Para um positivista, um fato é um fato, ele não 'nasce', não tem historicidade. A provocação de Fleck não é só com a ideia de gênese, mas também com a de desenvolvimento. Essa forma de construtivismo de Fleck realmente foi revolucionária. Benjamin também foi muito influenciado por essa ideia construtivista; segundo ele, não existe fato no passado, o que existe é uma construção do passado a partir do presente; com o avanço do presente essa construção se altera, se desenvolve. Por isso acho que os dois são perfeitamente associáveis. Creio que Fleck acabou inaugurando, juntamente com Kuhn, um estilo de pensamento, a ideia do paradigma. Aliás, ele usa duas vezes o termo paradigma em alemão, o que é um ponto importante. Parece-me que a ideia de estilo de pensamento é bem próxima à de paradigma.

Mariana - Gostaria de lembrar o autor italiano Primo Levi, que também foi um sobrevivente dos campos de concentração, e também foi cientista, químico. Primo Levi diz que traduzir é olhar um texto no microscópio e ver suas entranhas. Talvez haja alguma afinidade entre o trabalho de um tradutor e o de um microbiologista como Fleck. O trabalho de tradução exige uma leitura esmiuçada do texto, olhar realmente, examinar as entranhas do texto, aprender a ver.

\section{REFERÊNCIAS}

BERTOMEU-SÁNCHEZ, José Ramón et al. Scientific and technological textbooks in the European periphery. Science and Education, London, v.15, p.657-665. 2006.

CONDÉ, Mauro Lúcio Leitão.

Prefácio à edição brasileira. In: Fleck, Ludwik. Gênese e desenvolvimento de um fato científico. Trad., Georg Otte, Mariana Camilo de Oliveira. Belo Horizonte: Fabrefactum. p.VIII-XVIII. 2010.

FLECK, Ludwik.

Gênese e desenvolvimento de um fato científico.

Trad., Georg Otte, Mariana Camilo de Oliveira. Belo Horizonte: Fabrefactum. 2010.
KUHN, Thomas Samuel.

A estrutura das revoluções científicas. São Paulo: Perspectiva. 2006.

PYENSON, Lewis.

Functionaries and seekers in Latin America: missionary diffusion of the exact sciences, 18501930. Quipú, Mexico, v.2, p.387-420. 1985.

SCHROEDER-GUDEHUS, Brigitte.

Les scientifiques et la paix. Montréal: Les Presses de l’Université de Montréal. 1978.

SECORD, James A.

Knowledge in transit. Isis, Chicago, v.95, n.4, p.654-672. 2004.

\section{$\rightarrow \rightarrow \rightarrow<<$}

